\title{
New-born with Cervical Ectopic Thymus: An Uncommon Developmental Disorder Which Has to be Consider in the Differential Diagnosis of Unilateral Neck Mass in Children
}

\author{
Elisa Pani ${ }^{1 *}$, Noemi Cantone ${ }^{1}$, Aldo Naselli ${ }^{\mathrm{i}}$, Bruno Noccioli ${ }^{1}$ and Enrico Ciardini ${ }^{3}$ \\ ${ }^{1}$ Neonatal and Emergency Surgery Unit, Meyer Children Hospital, Italy \\ ${ }^{2}$ Neonatal Intensive Care Unit, Santa Chiara Hospital, Italy \\ ${ }^{3}$ Pediatric Surgery Unit, Santa Chiara Hospital, Italy
}

Submission: January 10, 2020; Published: February 06, 2020

*Corresponding author: Elisa Pani, Neonatal and Emergency Surgery Unit, Meyer Children Hospital, viale Pieraccini 24, 50139, Florence (FI), Italy

Keywords: Ectopic cervical thymus; New-born; Neck masses; Children; Pediatric age; MRI

\section{Case Report}

The aim of this paper is to report an unusual case of ectopic cervical thymus (CET) in a one-month-old infant and to underline the importance of considering it in the differential diagnosis of neck masses in children. A one-month-old male infant was referred to our Emergency Department for evaluation of a right-sided neck swelling, which was noted by his parents about 2 days before. The mother's pregnancy (medically assisted procreation) was full term and uncomplicated. The patient had never required admission to the hospital or surgery. Family history was negative for thyroid disease and malignancy. On physical examination, his height and weight were normal in his peers. Vital signs were normal. The cervical mass was soft, mobile, painless, and $4 \times 3-\mathrm{cm}$ rounded, in the right submandibular region without a palpable margin. No overlying skin changes, or pits were evident. No palpable cervical lymph nodes and history of difficulty in feeding, breathing, and crying were present. Past medical history was unremarkable and without a history of radiation exposure. His thyroid gland was not enlarged. Bio humoral work up included full blood count, electrolytes, tumour markers (aFP, bHCG, CEA, Ca 19-9), thyroid function, inflammatory parameters; we did also the immunological exams (lymphocyte and NK population, Ig G, Ig A, Ig M count, vanilmandelic acid and $\mathrm{T}$ cell receptor excision circles); all values resulted within range whereas ultrasonography revealed a nonhomogeneous, mainly cystic structure. On magnetic resonance imaging (MRI) examination (Figure 1), a homogenous mass was identified. The mass was 4 x $3 \mathrm{~cm}$ in diameter, slightly hyperintense on T1-weighted images and was markedly hyperintense on T2-weighted images. The signal characteristics reflected that of the normal-appearing thymus gland in the right upper mediastinum. The lesion determined moderate compression of adjacent structures, particularly the parotid gland behind. The mass had features compatible with ectopic thymic tissue. Initially, agree with onco-haematologists and radiologists, we decided to wait and to follow up the baby clinically and with an ultrasound after two and four weeks. During the second check, we noticed that the mass slightly grew up and at the ultrasound the dimensions were increased. Therefore, after careful preparations, at the age of 3 months, the patient underwent a complete excision of the mass under general anesthesia (Figure 2). We used routine cervical approach, and found the mass was soft, yellow white (Fig. 3), with clear margins and located in the carotid triangular area, posterior to the sternocleidomastoid, deeper to it are arteria carotis communis, carotid artery bifurcation and jugular vein. The postoperative course was unremarkable, and the wound healed well. The patient was discharged on the $6^{\text {th }}$ postoperative day. The final histopathological report confirmed the diagnosis of ectopic thymus. 

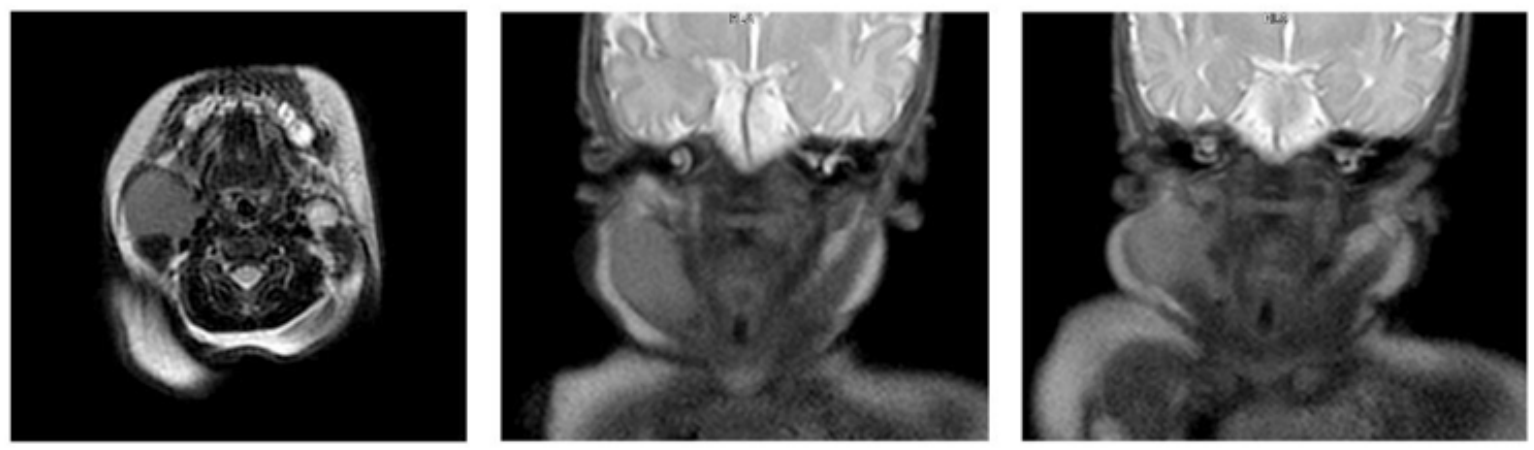

Figure 1: MRI: The mass had features compatible with ectopic thymic tissue.

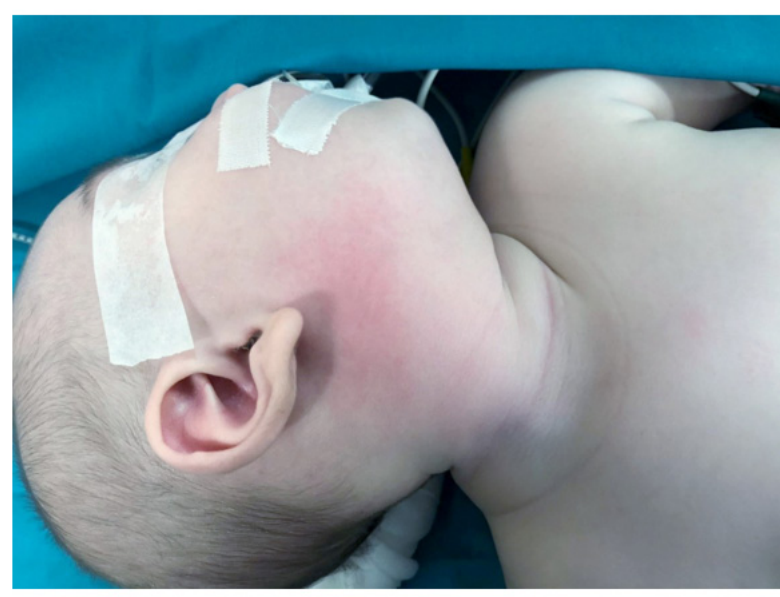

Figure 2: The patient with the right-sided neck swelling.

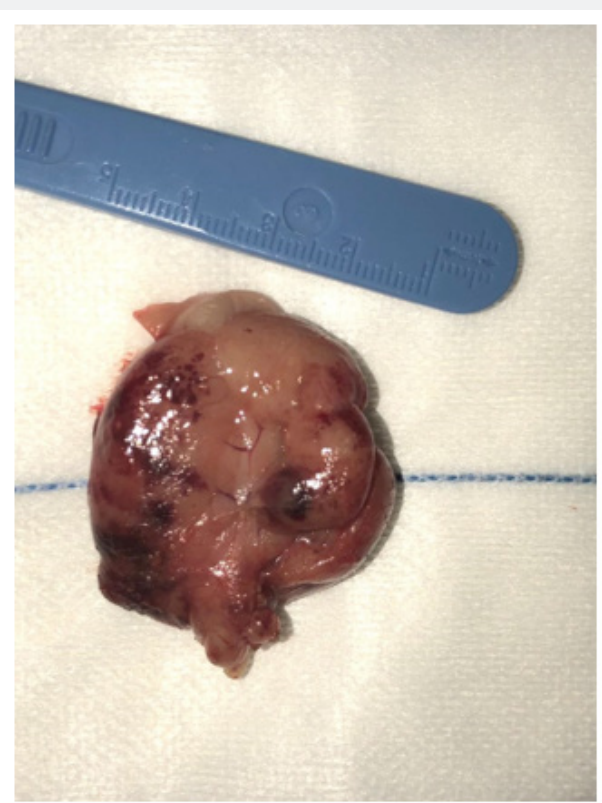

Figure 3: The ectopic thymus after the surgical excision. 


\section{Brief Discussion}

Ectopic thymic tissue may be placed anywhere along the cervical pathway of the thymopharyngeal duct [1] from the mandible angle to the manubrium of the sternum. These migrational anomalies may represent an unusual cause of pediatric neck lump but it is rarely considered in the differential diagnosis of neck swellings. To date, the real incidence of CET is still unknown yet; to our knowledge, there are not more than 130 cases reported till now, with about $10 \%$ occurring in infants [1]; it has unusually been reported preoperatively in the literature, in fact it is generally identified incidentally at autopsy or postoperative pathologic examination. Histologically, an ectopic thymus can either be cystic or solid. Nowak et al. [2] reviewed 91 cases of CET: 65 cases were cystic forms, more common than the solid forms (26 cases). They also reported that CET usually occurs between the ages of 2 and 13 years. In a review of 46 CET cases, 39 (85\%) were male, and in 22 (56\%) of these, the mass was detected on the right side [3]. The most frequently presenting symptom is painless swelling. Other symptoms, such as stridor, dyspnea, and/or dysphagia caused by compression of the trachea and/or oesophagus, may occur in $10 \%$ of cases [4]. The thymus is a specialized organ in the immune system: its functions are the "teaching" of T-lymphocytes and the production and excretion of thymosin's and hormones [5]. In patients with a CET, only half or less of the organ can be present in the chest, particularly on the side of the mass: presurgical recognising of existence of normal mediastinal thymus is imperative to avoid over-investigation, or biopsy/surgery with unintended total thymectomy, and subsequent immunodeficiency, specifically in infants and children. The clear preoperative diagnosis of CET is difficult and hardly made preoperatively. In almost all reviewed children, definitive diagnosis has relied on histopathologic examination after surgery [5]. CET is usually misdiagnosed as cystic hygroma, cystic teratoma, lymphoproliferative disorders, reactive adenopathy, and vascular tumours [1]. MRI can help as in the diagnosis of CET, determining if the mass's density is similar to that of normal thymus, as to demonstrate the presence of a mediastinal thymus. Fine-needle biopsy combined with flow cytometry analysis have been used in the pediatric population $[1,6]$. But the sensitivity and specificity for fine-needle biopsy of thymic tissue are not known in the children.

The natural history of the CET is unknown. Nearly all cases reported in the literature have been surgically removed. Schloegel and Gottschall [7] proposed a clinical algorithm for the management of CET and suggested that "wait and watch" is the ideal choice for these patients. But due to the lack of reports demonstrating that CET would atrophy after puberty, we consider that pathological examination at the moment is still the definite method of diagnosis. In view of this, we advise that excision is a good option for CET, not only to obtain pathology specimens but also to correct facial asymmetry and avoid clinical symptoms. The best age above which safe removal of the thymus can be performed has not been determined. Accordingly, an accurate evaluation of the presence of the normal mediastinal thymus should be undertaken prior to removal of an ectopic cervical thymus, especially in children younger than one year of age, to prevent the risk of immunocompromised [8-10]. For our patient, we chose to conduct the total excision of the lesion based on what previously declared, but also because of the growth speed of the mass, which was rather rapid. Moreover, in our department, this kind of neck tumour was usually resected, and other conservative management methods were not generally practiced. To conclude, ectopic cervical location of the thymus is a very rarely diagnosed developmental disorder in children. Our case highlights the role of histopathology to confirm the correct diagnosis, the importance of investigating the mediastinal thymus and immunology status before surgery. Although difficult to differentiate from other conditions, it is important for clinicians to be aware of its rarity and it has to be considered in the differential diagnosis of unilateral solid-cystic neck mass in pediatric age.

\section{Learning Points}

1. Ectopic cervical thymus must be considered in the differential diagnosis of unilateral neck masses in children.

2. Before surgery, it is mandatory to scan the presence of a mediastinal thymus to avoid a total thymectomy; the best radiological exam to demonstrate it is the MRI.

3. Consider, before surgery, to make all immunology tests.

\section{Conflicts of interest}

All authors declare that they have no conflict of interests.

\section{References}

1. Jun Wang, Honghai Fu, Huawei Yang, Lizhen Wang, Yue He (2011) Clinical management of cervical ectopic thymus in children. J Pediatr Surg 46(8): 33-36.

2. Nowak PA, Zarbo RJ, Jacobs JR (1988) Aberrant solid cervical thymus. Ear Nose Throat J 67(9): 670-677.

3. Zielke AM, Swischuk LE, Hernandez JA (2007) Ectopic cervical thymic tissue: can imaging obviate biopsy and surgical removal. Pediatr Radiol 37(11): 1174-1177.

4. Sturm-O'Brien AK, Salazar JD, Byrd RH, Popek EJ, Giannoni CM, et al. (2009) Cervical thymic anomalies-the Texas Children's Hospital experience. Laryngoscope 119(10): 1988-1993.

5. Zhang Zhaoqiang, Zhang Qingbin, Chen Lei, Chen Dan, Chen Yu, et al. (2012) Infant ectopic cervical thymus one case report: Diagnostic and management difficulties. J Craniomaxillofac Surg 40(8): 701-705

6. Tunkel DE, Erozan YS, Weir EG (2001) Ectopic cervical thymic tissue: diagnosis by fine needle aspiration. Arch Pathol Lab Med 2001; 125:278-81.

7. Schloegel LJ, Gottschall JA (2009) Ectopic cervical thymus: is empiric surgical excision necessary. Int J Pediatr Otorhinolaryngol 73(3): 475479 .

8. Wells WJ, Parkman R, Smogorzewska E, Barr M (1998) Neonatal thymectomy: does it affect immune function? J Thorac Cardiovasc Surg 115(5): 1041-1046. 
9. Brearly S, Gentle TA, Baynham MI, Roberts KD, Abrams LD, et al. (1987) Immunodefiency following neonatal thymectomy in man. Clin Exp Immunol 70(2): 322-327.
10. Khariwala SS, Nicollas R, Triglia JM, et al. (2004) Cervical presentations of thymic anomalies in children. Int J Pediatr Otorhinolaryngol 68(7): 909-914.

\section{Your next submission with Juniper Publishers will reach you the below assets}

- Quality Editorial service

- Swift Peer Review

- Reprints availability

- E-prints Service

- Manuscript Podcast for convenient understanding

- Global attainment for your research

- Manuscript accessibility in different formats

( Pdf, E-pub, Full Text, Audio)

- Unceasing customer service

Track the below URL for one-step submission https://juniperpublishers.com/online-submission.php 